\title{
Biochemical Responses of Soybean (Glycine max L. Merr.) to Proton Beam Irradiation
}

\author{
Juhyun Im, Jonghan Ko, Han-Yong Kim, Bo-Keun Нa* \\ Division of Plant Biotechnology, Chonnam National University, Gwangju 61186, Korea
}

\begin{abstract}
The present study evaluated the biochemical effects of proton beam irradiation in soybean. Seeds of two Korean elite cultivars (Kwangan and Pungsannamul) were irradiated by a 57-MeV proton beam in the range of 50-400 Gy. We measured the contents of malondialdehyde (MDA), antioxidant enzymes, and chlorophyll. MDA contents in proton beam-irradiated plants were higher than those in control plants. The activity of antioxidant enzymes differed between the two cultivars. In Kwangan, ascorbate peroxidase (APX) activity increased by $29 \%$ relative to the control at 55 Gy and decreased by $58 \%$ at 308 Gy. Superoxide dismutase (SOD) and peroxidase (POD) activities decreased by 47 and $25 \%$ relative to the control at 55 Gy and recovered to 87 and $56 \%$ of that at 55 Gy with 172 Gy and 117 Gy, respectively. In Pungsannamul, APX and SOD decreased by 32 and $35 \%$ relative to the control at 62 Gy, with the highest value observed at $243 \mathrm{~Gy}$. In terms of the chlorophyll content, the two varieties responded similarly to proton beam irradiation, whereas in Kwangan, no significant reduction was observed above 100 Gy when compared with the control. Proton beam irradiation affected chlorophyll $\mathrm{b}$ more than chlorophyll a. These results show that the activity of antioxidant enzymes decreased in response to irradiation with approximately $50 \mathrm{~Gy}$ proton beams, then increased gradually with increasing doses, followed by a moderate decrease at higher doses. According to correlation with MDA contents and antioxidant enzyme activities, defense system of Pungsannamul was less activated by proton-beam irradiation than that of Kwangan.
\end{abstract}

Keywords Soybean, Mutant, Proton beam, Biochemical response

\section{INTRODUCTION}

New varieties have been developed through crossbreeding techniques; however, hybridization with the same or very closely related species is limited in its ability to create new and diverse cultivar traits (Lee et al. 2015a). Mutation breeding is an alternative method used to generate variation and is used to improve agronomic traits, such as resistance to stress, physical parameters of grain, and nutritional value (Ling et al. 2013; Lee et al. 2015a). Mutations are induced by chemical or physical mutagens. Chemical mutagens such as ethylmethanesulfonate (EMS), $\mathrm{N}$-nitroso- $N$-methylurea (NMU) and colchicine have long been used to develop new traits in crops, but these che- micals are carcinogenic and difficult to use (Sung et al. 2013). Ionizing radiation can overcome the limitations of chemical treatment and generate new mutations over a short period of time (Lee et al. 2015b).

For 80 years, gamma-rays have been used to induce mutations and generate new agronomic traits, mainly in crop mutation breeding programs. Gamma-rays emitted from a ${ }^{60} \mathrm{Co}$ source are a type of low linear energy transfer $(\mathrm{LET}=0.2 \mathrm{keV} / \mu \mathrm{m})$ radiation, and induce mutations ranging from point mutations to chromosomal aberrations (Du et al. 2014). Recently, high energy ion beams, including proton, helium, carbon, and argon ions, have been considered as new effective mutagens. Ion beams were shown to exhibit greater biological effects on growth

Received March 14, 2017; Revised April 20, 2017; Accepted April 24, 2017; Published June 1, 2017

*Corresponding author Bo-Keun Ha, bkha@jnu.ac.kr, Tel: +82-62-530-2055, Fax: +82-62-530-2059 
inhibition and lethality than gamma-rays (Tanaka et al. 2010). In addition, ion beams induced a high frequency and a broad spectrum of mutant phenotypes (Tanaka et al. 2010).

The biological effects of ionizing radiation are induced in multiple steps, from the initial absorption of energy to the final biological injury (Esnault et al. 2010). The initial reactions include the formation of an $\mathrm{H}$ atom and an $\mathrm{OH}$ radical following water radiolysis. $\mathrm{OH}$ radicals are the most highly reactive oxygen species (ROS) (Gill and Tuteja 2010). OH radical rapidly attacks macromolecules and leads to irreparable metabolic dysfunction and cell death (Scandalios 1993). In addition, water radiolysis produces secondary ROS such as hydrogen peroxide $\left(\mathrm{H}_{2} \mathrm{O}_{2}\right)$, superoxide anion $\left(\mathrm{O}_{2}{ }^{-}\right)$, hydroxyl radicals $(\mathrm{OH})$, and singlet oxygen (Wi et al. 2007). ROS is also generated by various metabolic pathways, such as photorespiration and the oxidation of fatty acids in mitochondria and chloroplasts (Garg and Manchanda 2009; Weisany et al. 2012), as well as biotic and abiotic factors, such as drought, salinity, chilling, metal toxicity, UV-B radiation, and pathogen attack (Sharma et al. 2012; Weisany et al. 2012). The high accumulation of ROS by ionizing radiation can cause oxidative damage to lipids, proteins, and DNA, which result in increased peroxidation (degradation) of lipids, site-specific amino acid modification, fragmentation of peptide chains, DNA-strand breakage, and various nucleotide modifications (Sharma et al. 2012).

Conversely, excess accumulation of ROS in plants triggers the activity of antioxidant enzymes, such as superoxide dismutase (SOD), peroxidase (POD), ascorbate peroxidase (APX), and catalase (CAT) (Lee et al. 2016). SOD acts as the first enzyme in the scavenging process, converting superoxide radicals to $\mathrm{H}_{2} \mathrm{O}_{2}$ ( $\mathrm{Kim}$ et al. 2012). APX and POD play important roles in $\mathrm{H}_{2} \mathrm{O}_{2}$ detoxification in cells (Foyer and Noctor 2005; Wi et al. 2007). APX uses ascorbate as the reducing agent of $\mathrm{H}_{2} \mathrm{O}_{2}$ (Foyer and Noctor 2005). CAT also dismutates $\mathrm{H}_{2} \mathrm{O}_{2}$ into $\mathrm{H}_{2} \mathrm{O}$ and $\mathrm{O}_{2}$, mostly in peroxisomes (Gill and Tuteja 2010). Evaluating the contents of antioxidant enzymes can be used to determine the level of oxidative stress caused by ROS.

Proton beams are composed of particles with a mass and electrical charge, and a lower LET than heavy ion beams
(Lee et al. 2015b). In this study, we irradiated soybean seeds of two elite Korean varieties with different doses of proton beams. We measured physiological parameters such as antioxidant enzymes, chlorophyll, and malondialdehyde (MDA) to study the effects proton-beam irradiation.

\section{MATERIALS AND METHODS}

\section{Plant material}

Two Korean soybean cultivars including 'Pungsannamul' and 'Kwangan' were used in this study. Pungsannamul has a small seed size (10.6 g per 100 seeds) and is suitable for soybean sprouts (Suh et al. 1997). Kwangan also has a small seed size ( $11.6 \mathrm{~g}$ per 100 seeds) and is suitable for soybean sprouts (Lee 2012).

\section{Proton-beam irradiation}

The seeds of all cultivars were irradiated using a proton beam at $57 \mathrm{MeV}$ with $100 \mathrm{MeV}$ proton linear accelerator of the Korea Multi-Purpose Accelerator Complex (KOMAC) in Gyeongju, Korea. Pungsannamul was irradiated at doses of 62, 110, 168, 243, and $316 \mathrm{~Gy}$. Kwangan was irradiated at doses of 55, 117, 172, 246, and 308 Gy. Irradiated and non-irradiated seeds were planted in 50-cell plastic trays $(27 \times 53 \times 11.2 \mathrm{~cm}$ ) filled with potting mix (coco peat, peat moss, zeolite, pearlite, caldolomite, wetting agent, and fertilizer) and cultured in a greenhouse. Each seed was planted in an individual cell. Three replicates were performed for each treatment, and each replicate comprised of one tray of 50 plants. Leaves from irradiated and non-irradiated plants were harvested 4 weeks after planting and stored at $-80^{\circ} \mathrm{C}$ for biochemical analyses.

\section{Measurement of MDA content}

The extent of lipid peroxidation was determined by measuring MDA content using the trichloroacetic acid (TCA) method as determined by Zhang et al. (2011). Leaf samples $(0.2 \mathrm{~g})$ were homogenized with $1.5 \mathrm{~mL} 10 \%$ TCA for 30 minutes in a refrigerator. Samples were vigorously vortexed before centrifugation at $10,000 \mathrm{~g}$ for 20 minutes at $4^{\circ} \mathrm{C}$ and supernatants were mixed with an equal volume of 
$0.67 \%$ 2-thiobarbituric acid. The mixtures were heated at $95^{\circ} \mathrm{C}$ for 30 minutes followed by cooling on ice for 5 minutes and centrifugation at $10,000 \mathrm{~g}$ for 5 minutes at $4^{\circ} \mathrm{C}$. The MDA concentrations were determined by measuring the absorbance at 450, 532, and $600 \mathrm{~nm}$ using an Epoch microplate spectrophotometer (Bio Tek Instruments Inc., USA) and were calculated as follows:

$$
\begin{gathered}
\text { - } \operatorname{MDA}\left(\mu \mathrm{mol} \mathrm{L}^{-1}\right)=6.45 \times(\mathrm{A} 532-\mathrm{A} 600)-0.56 \times \\
\mathrm{A} 450=\mathrm{C} 1 \\
\text { - MDA }\left(\mathrm{nmol}[\mathrm{g} \mathrm{FW}]^{-1}\right)=\mathrm{C} 1 \times \mathrm{V} / \mathrm{W}
\end{gathered}
$$

\section{Measurement of antioxidant enzymes}

The total soluble protein content in irradiated and non-irradiated plants was determined using the Bradford method (Bradford 1976). Powdered samples (0.2 $\mathrm{g}$ each) in a $2.0-\mathrm{mL}$ tube were mixed with $1.2 \mathrm{~mL} 0.2 \mathrm{M}$ potassium phosphate buffer ( $\mathrm{pH} 7.8+0.1 \mathrm{mM}$ EDTA) and homogenized thoroughly, followed by centrifugation at 10,000 rpm for 20 minutes at $4^{\circ} \mathrm{C}$. To determine the total soluble protein content, $2 \mu \mathrm{L}$ of supernatant was added to $8 \mu \mathrm{L}$ $\mathrm{ddH}_{2} \mathrm{O}$ and $190 \mu \mathrm{L} 1 \mathrm{X}$ dye reagent. The absorbance at 595 $\mathrm{nm}$ was determined using a spectrophotometer. The absorbance was compared to a standard curve plotted using bovine serum albumin (BSA) (Bio-Rad Laboratories, Inc., USA) with standard concentrations of $0,125,250,500$, $750,1,000,1,500$, and $2,000 \mu \mathrm{g} / \mathrm{mL}$. The total soluble protein content of the samples is expressed in $\mathrm{mg} / \mathrm{g}$ fresh weight (FW) of plant material.

APX activity was measured using the method described by Nakano and Asada (1981). The reaction solution contained potassium phosphate buffer $(\mathrm{pH} 7.0), 5 \mathrm{mM}$ ascorbate, $1 \mathrm{mM}$ EDTA, and $50 \mathrm{mM} \mathrm{H}_{2} \mathrm{O}_{2}$. Enzyme activity was determined from the initial rate of the reaction using the extinction coefficient of ascorbate, and the absorbance was monitored at $290 \mathrm{~nm}$ using a UV spectrophotometer for 5 minutes.

SOD activity was measured by monitoring the inhibition of the photochemical reduction of nitroblue tetrazolium (NBT). The reaction mixture consisted of $50 \mathrm{mM}$ potassium phosphate (pH 7.8), $100 \mathrm{mM}$ EDTA, $1 \mathrm{mM}$ NBT, $100 \mathrm{mM}$ methionine, $0.2 \mathrm{mM}$ riboflavin, and $1 \%$ Triton-X100. The reaction mixture was placed under strong light conditions for 10 minutes. SOD activity was measured at a wavelength of $560 \mathrm{~nm}$ by UV spectrophotometry (Beyer and Fridovich 1987).

POD activity was measured using the method described by Kim et al. (2012). The reaction mixture contained 100 $\mathrm{mM}$ potassium phosphate ( $\mathrm{pH}$ 6.0), $100 \mathrm{mM}$ pyrogallol, and $100 \mathrm{mM} \mathrm{H}_{2} \mathrm{O}_{2}$. POD activity was measured by monitoring changes in the absorbance at $420 \mathrm{~nm}$ for 1 minute, which resulted from the oxidation of pyrogallol.

\section{Measurement of chlorophyll content}

Fresh leaf samples $(0.2 \mathrm{~g})$ were ground in liquid nitrogen using a mortar and pestle, and homogenized in $1.5 \mathrm{~mL} 80 \%$ acetone. The homogenized samples were then kept overnight in the dark at $4^{\circ} \mathrm{C}$. The samples were centrifuged at $3,000 \mathrm{rpm}$ at $4^{\circ} \mathrm{C}$ for 15 minutes. The supernatant was transferred to a new tube. The absorbance of each supernatant at 645 and $663 \mathrm{~nm}$, and concentrations, were calculated as previously described ( $\mathrm{Ni}$ et al. 2009).

\section{Statistical analysis}

In this study, three replicates were used to assess biochemical responses. The results were subjected to analysis of variance using SAS version 9.1 (SAS Institute Inc., Cary, NC, USA). Separation of means was performed using the DMRT test at $P<0.05$.

\section{RESULTS}

\section{Effect of proton beam irradiation on MDA content}

In this study, the seeds of two soybean cultivars were irradiated with five different doses of proton beam, and the MDA content was determined using the leaves of 4-week-old soybean plants (Fig. 1). In Kwangan, there was no significant difference among the control and proton beam-irradiated plants. However, all proton beam-irradiated plants showed higher MDA contents than the control plants. In particular, the MDA content of Kwangan peaked at a dose of $55 \mathrm{~Gy}$, and then decreased with increasing doses. In Pungsannamul, the MDA contents of treated plants tended to increase with increasing dose. A dose of 316 Gy resulted in the highest MDA value, which was increased by $46 \%$ in comparison to the control. 

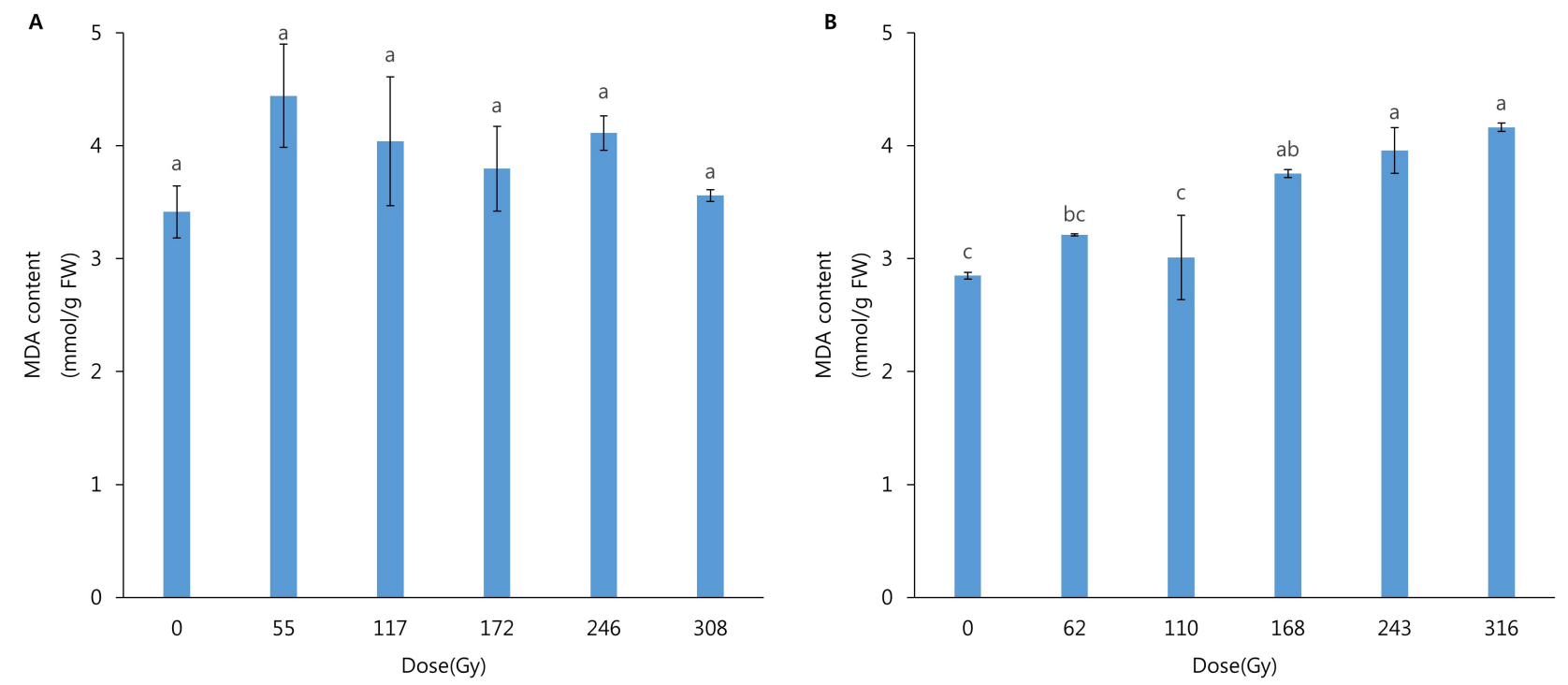

Fig. 1. Effect of proton beam irradiation on the total MDA content of leaves from soybean cultivars. Mean separation within columns by LSD test at $P=0.05$. (A) Kwangan (B) Pungsannamul.
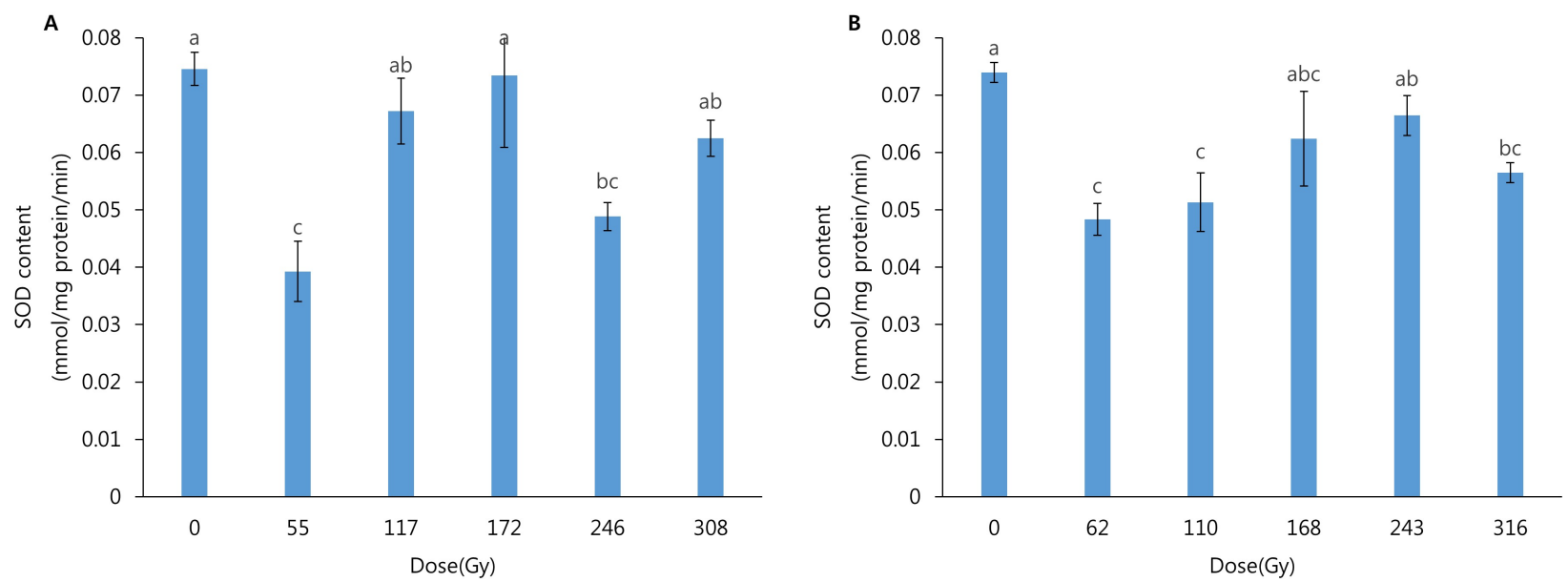

Fig. 2. Effect of proton beam irradiation on the total SOD activity of leaves from soybean cultivars. Mean values were separated using the DMRT test at $P<0.05$. (A) Kwangan (B) Pungsannamul.

\section{Effect of proton beam-irradiation on antioxidant enzymes}

To evaluate the effect of proton beam treatments on the activities of antioxidant enzymes, SOD, POD, and APX activities were measured in two soybean cultivars. In both cultivars, the highest SOD activity was found in control plants and the lowest SOD activity was observed in plants irradiated with proton beams below 100 Gy (Fig. 2). In
Kwangan, SOD activity decreased to $48 \%$ that of the control at $55 \mathrm{~Gy}$ and recovered to $87 \%$ that of $55 \mathrm{~Gy}$ at 172 Gy. In Pungsannamul, SOD activity decreased by $35 \%$ that of the control at $62 \mathrm{~Gy}$, and recovered to $38 \%$ that of $62 \mathrm{~Gy}$ at $243 \mathrm{~Gy}$. The recovered SOD activity in both Kwangan and Pungsannamul remained lower than that of the control. Furthermore, the SOD activities of both cultivars decreased again in response to proton beam-irradiation over $300 \mathrm{~Gy}$. In Kwangan, POD activity followed a similar pattern to 

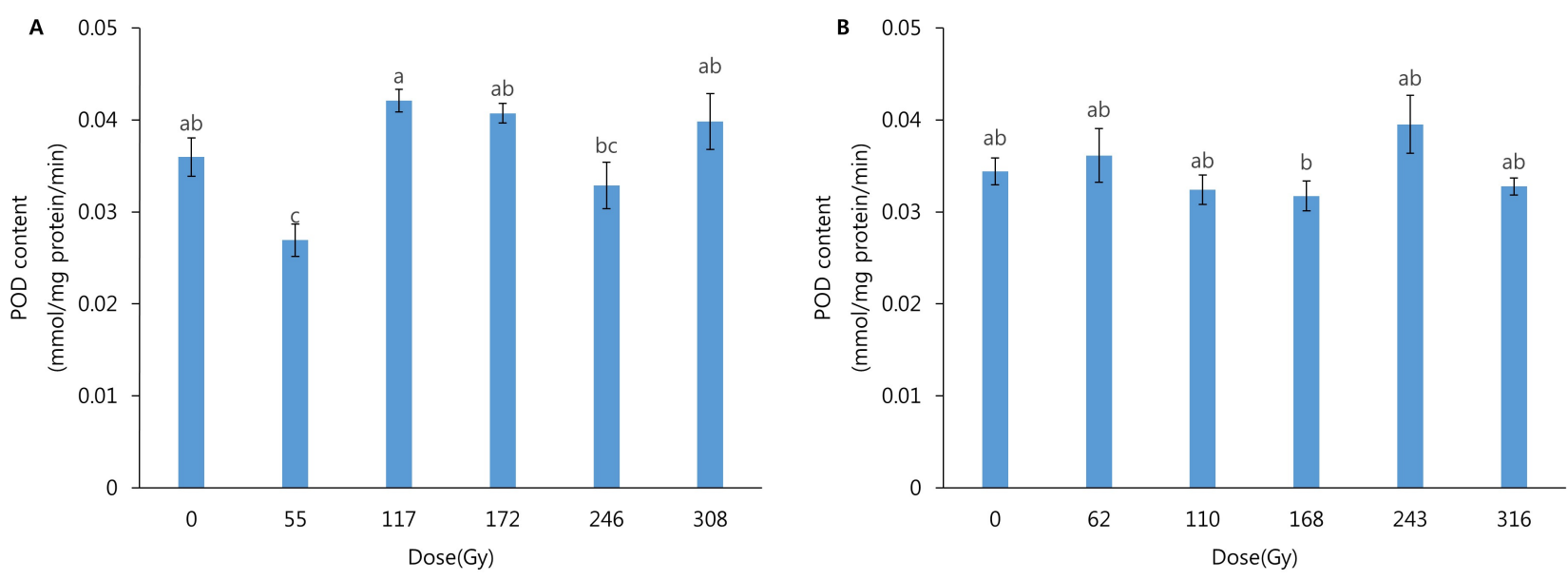

Fig. 3. Effect of proton beam irradiation on the total POD activity of leaves from soybean cultivars. Mean values were separated using the DMRT test at $P<0.05$. (A) Kwangan (B) Pungsannamul.
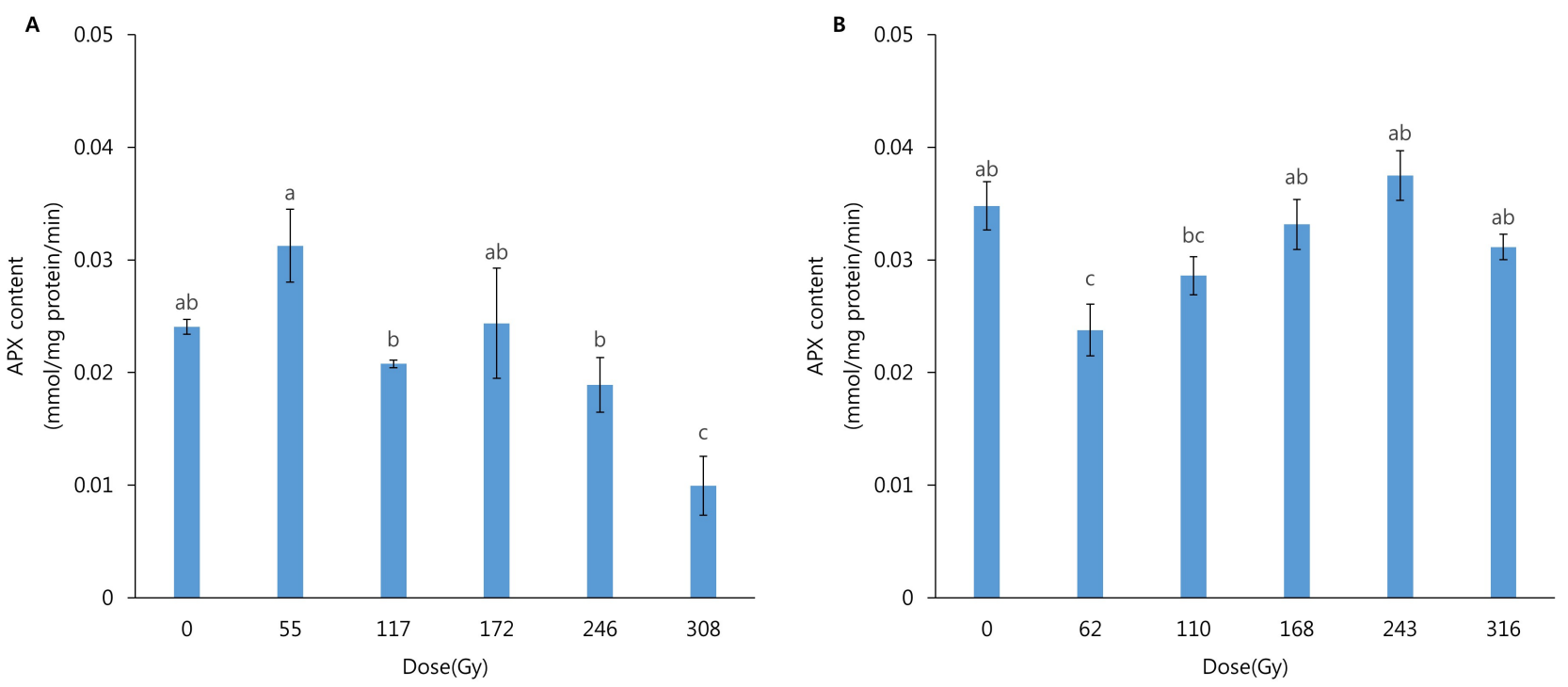

Fig. 4. Effect of proton beam irradiation on the total APX activity of leaves from soybean cultivars. Mean values were separated using the DMRT test at $P<0.05$. (A) Kwangan (B) Pungsannamul.

SOD activity. POD activity decreased to $25 \%$ that of the control at $55 \mathrm{~Gy}$ and recovered to $56 \%$ that of $55 \mathrm{~Gy}$ at the dose of $117 \mathrm{~Gy}$. Then, POD activity decreased again at doses exceeding $200 \mathrm{~Gy}$. In Pungsannamul, the highest value observed was $114 \%$ that of the control at $243 \mathrm{~Gy}$, and the lowest value was $92 \%$ that of the control at 168 Gy (Fig. 3).

APX isoforms have a higher affinity for $\mathrm{H}_{2} \mathrm{O}_{2}$ than CAT or POD (mM range), which may play a more crucial role in the management of ROS during stress (Gill and Tuteja 2010; Sharma et al. 2012). The APX activities of the two cultivars showed a reverse tendency. In Kwangan, a dose of 55 Gy resulted in the highest activity, which was increased by $29 \%$ compared with the control. Conversely, a dose of 308 Gy resulted in the lowest value, which decreased by 58\% compared with the control. In Pungsannamul, APX activity seemed to follow a similar trend to SOD activity. A dose of 62 Gy resulted in the lowest value, decreasing to $32 \%$ of that observed in the control plant. APX activity increased with increasing proton beam dose, up to $243 \mathrm{~Gy}$, after which activity decreased again (Fig. 4). 


\section{Effect of proton beam irradiation on chlorophyll contents}

The chlorophyll content of two varieties, Kwangan and Pungsannamul, followed a similar tendency, such that the content of chlorophyll $\mathrm{b}$ and total chlorophyll increased in response to low-dose proton beams and decreased above 100 Gy (Fig. 5). Borzouei et al. (2010) reported an increase in chlorophyll content in wheat seedlings irradiated by low-dose gamma-rays, which might be due to growth stimulated by gamma-ray irradiation. In the present study, proton beams around 50 Gy increased plant height compared with the control (data not shown). Therefore, low-dose proton beams could also stimulate plant growth resulting in some increase in chlorophyll content.

In response to proton beams above $100 \mathrm{~Gy}$, chlorophyll $\mathrm{b}$ and total chlorophyll contents in Kwangan were not significant different compared with those of the control, while Pungsannamul showed a significant reduction of chlorophyll $\mathrm{b}$ and total chlorophyll contents compared with the control.

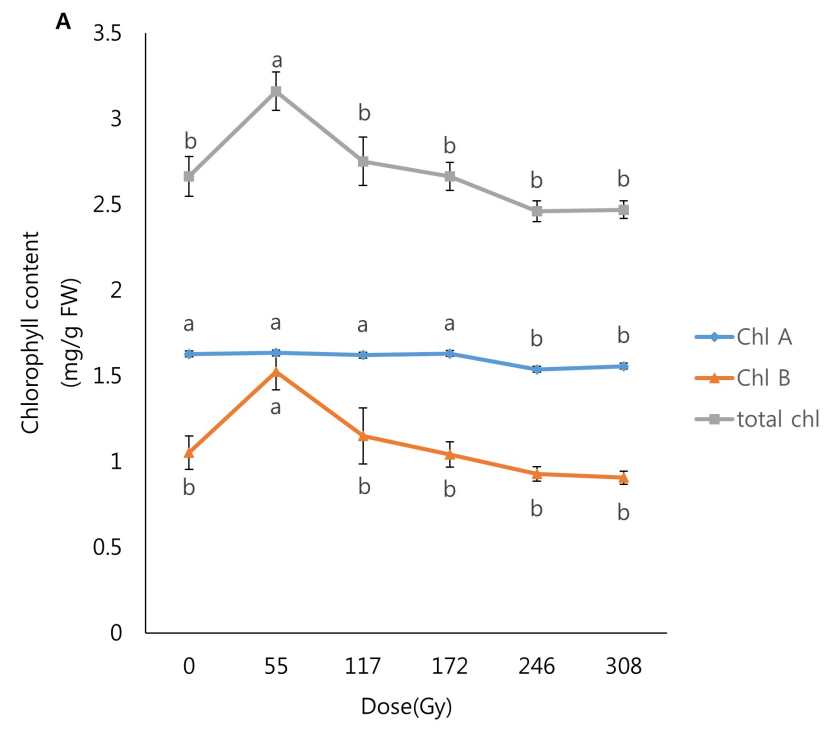

\section{DISCUSSION}

In the present study, biochemical responses of two proton beam-irradiated soybean cultivars are reported. In Kwangan, the MDA contents of all treatments were slightly higher than that of control, but these increases did not show significant different. In Pungsannamul, the MDA content increased significantly in response to increasing proton beam dose and the increase at a dose of $316 \mathrm{~Gy}$ was $46 \%$ compared to the control. Lipid peroxidation is a sign of oxidative damage, and the level of lipid peroxidation can be determined by measuring the MDA content, which is an end-product of lipid peroxidation, and has been used as indicator of plant membrane stress (Kim et al. 2015; Lee et al. 2015b). Lee et al. (2015b) reported that MDA contents increased in response to increasing gamma-ray and proton beam doses, and that Cymbidium irradiated with proton beams at $100 \mathrm{MeV}$ showed higher MDA contents than Cymbidium irradiated with gamma-rays. In addition, Alikamanoglu et al. (2011) reported MDA content of irradiated soybean had similar tendency with that of Pungsannamul. However, the increase at 300 Gy gamma-ray exposures was $12 \%$ compared to non-irradiated controls. These results indicate that proton beams lead to greater

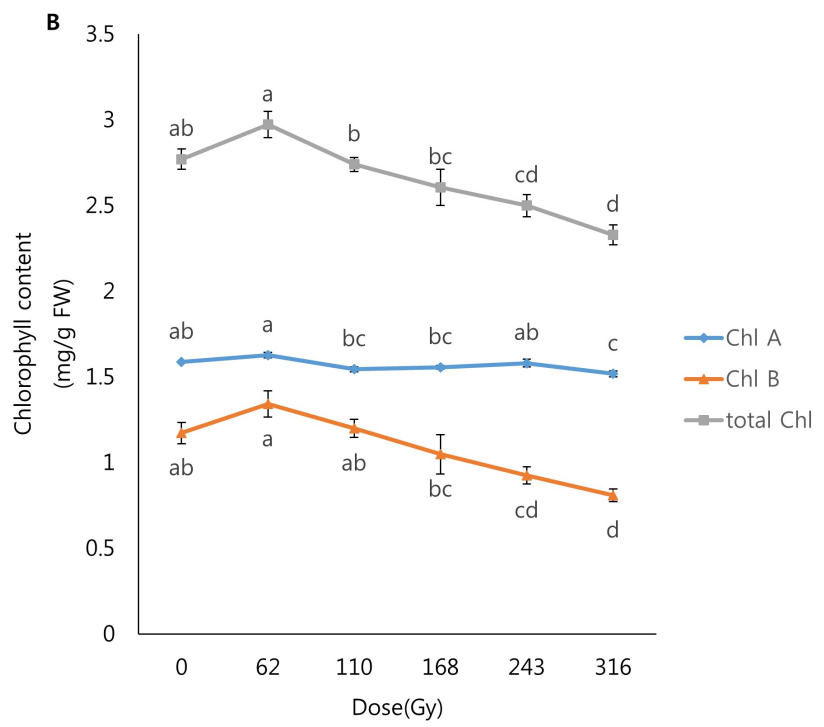

Fig. 5. Effect of proton beam irradiation on the chlorophyll content of the leaves of soybean cultivars. Mean values were separated using the DMRT test at $P<0.05$. (A) Kwangan (B) Pungsannamul. 
oxidative damage of plant membranes than gamma-ray.

Antioxidant enzymes play key roles in cellular defense mechanisms against oxidative damage induced by ROS. SOD enzymes represent the first-line defense against oxidative stress. The SOD activity of the two cultivars had followed a similar 'falling-rising-falling' pattern with increasing doses of proton beams. This 'falling-rising-falling' of SOD activity was also found in rice in response to $\mathrm{N}^{+}$ beams (Zhao et al. 2013). In addition, SOD and POD activities in Kwangan responded in a similar way to proton beam irradiation, while SOD and APX activities in Pungsannamul responded similarly. Furthermore, we found that SOD activity had the opposite effect on MDA content. The results of a previous study revealed similar results, such that SOD activity had a negative relationship with MDA content or lipid peroxidation because SOD scavenged superoxide, which interrupts vital biomolecules and inactivates CAT and POD (Esfandiari et al. 2007).

In the present study, the activity of antioxidant enzymes differed between cultivars. The sum of APX and POD activity below 200 Gy seemed to be similar trend in the two cultivars. Above $200 \mathrm{~Gy}$, the total activity reported for Pungsannamul was higher than that for Kwangan. According to Kim et al. (2012), diverse antioxidant response systems in higher plants have evolved, and different mechanisms exist for scavenging ROS generated by water radiolysis when exposed to different ionization treatments. This is because radio-sensitivity depends on chromosome density, DNA contents, the ability to restore damaged DNA, the activity of antioxidant enzymes, and the moisture content of a species or cultivar (Oh et al. 2003).

Reduced chlorophyll contents are a useful indicator of leaf senescence and an important parameter of physiological reactions to stresses (Kim et al. 2012). The highest value of total chlorophyll was observed following irradiation below 100 Gy and was gradually decreased in the two cultivars above 100 Gy. However, a significant decrease was only observed in Pungsannamul. Consistent with the present results, Ling et al. (2013) reported that the highest chlorophyll content appeared in response to $40 \mathrm{~Gy}$ and a reduction in chlorophyll content was observed above $100 \mathrm{~Gy}$ following irradiation with carbon ion beams in rice. Kalimullah et al. (2003) suggested that ${ }^{1} \mathrm{H}$ heavy-ion radiation inhibited chlorophyll biosynthesis. In addition, a reduction in the chlorophyll concentration was observed following irradiation due to the breakdown of the porphyrin ring of the chlorophyll molecule. Interestingly, high-dose irradiation induced noticeable structural changes in chloroplasts, which exhibited swollen and destructed thylakoids (Wi et al. 2007). In the same way as heavy-ion beam and gamma-ray irradiation, proton beams might destroy photosynthetic pigments and adversely affect the photosynthetic capacity of plants.

In this study, proton beam irradiation was also found to result in a greater reduction in the contents of chlorophyll b compared with chlorophyll a in both cultivars. Similar results have been reported in previous studies on Orthosiphon stamineus (Kiong et al. 2008) and Zea mays (Marcu et al. 2013) exposed to gamma irradiation, and Oryza sativa irradiated by carbon ion beams (Ling et al. 2013). This severe reduction in chlorophyll $b$ following ionizing radiation is due to the destruction of chlorophyll $b$ biosynthesis or degradation of its precursors (Ling et al. 2013). During photosynthesis, chlorophyll b is present only in the light harvesting antenna complex I (LHC I) and light harvesting antenna complex II (LHC II), while chlorophyll $\mathrm{a}$ is present in the photosystem cores and light harvesting antenna complexes (Voitsekhovskaja and Tyutereva 2015). Therefore, the reduced levels of chlorophyll b following ionizing radiation suggest that the LHC I and LHC II of photosystems are damaged.

The results of this study showed that proton beams affect soybean plants by inducing plant membrane damage and oxidative stress and reducing chlorophyll contents. The changes in antioxidant enzyme activities against oxidative damage were shown to be 'falling-rising-falling' pattern with increasing doses of proton beams in a cultivar-dependent manner.

\section{ACKNOWLEDGEMENTS}

This work was supported by a National Research Foundation of Korea (NRF) grant funded by the Korean government (MSIP: Ministry of Science, ICT and Future Planning; No. NRF-2016M2B2A4908203) and the Korea 
Institute of Planning and Evaluation for Technology in Food, Agriculture, Forestry, and Fisheries (IPET) through the Agri-Bio Industry Technology Development Program, as well as by the Ministry of Agriculture, Food and Rural Affairs (MAFRA), Republic of Korea (No. 315025-03-1-HD060).

\section{REFERENCES}

Alikamanoglu S, Yaycili O, Sen A. 2011. Effect of gamma radiation on growth factors, biochemical parameters, and accumulation of trace elements in soybean plants (Glycine $\max$ L. Merrill). Biol. Trace. Elem. Res. 141: 283-293.

Beyer WF, Fridovich I. 1987. Assaying for superoxide dismutase activity: some large consequences of minor changes in conditions. Anal. Biochem. 161: 559-566.

Borzouei A, Kafi M, Khazaei H, Naseriyan B, Majdabadi A. 2010. Effects of gamma radiation on germination and physiological aspects of wheat (Triticum aestivum L.) seedlings. Pak. J. Bot. 42: 2281-2290.

Bradford MM. 1976. A rapid and sensitive method for the quantitation of microgram quantities of protein utilizing the principle of protein-dye binding. Anal. Biochem. 72: 248-254.

Du Y, Li W, Yu L, Chen G, Liu Q, Luo S, et al. 2014. Mutagenic effects of carbon-ion irradiation on dry Arabidopsis thaliana seeds. Mutat. Res. Genet. Toxicol. Environ. Mutagen. 759: 28-36.

Esfandiari E, Shekari F, Shekari F, Esfandiari M. 2007. The effect of salt stress on antioxidant enzymes' activity and lipid peroxidation on the wheat seedling. Notulae. Botanicae. Horti. Agrobotanici. Cluj-Napoca 35: 48-56.

Esnault MA, Legue F, Chenal C. 2010. Ionizing radiation: Advances in plant response. Environ. Exp. Bot. 68: 231-237.

Foyer CH, Noctor G. 2005. Oxidant and antioxidant signalling in plants: a re-evaluation of the concept of oxidative stress in a physiological context. Plant Cell Environ. 28: 1056-1071.

Garg N, Manchanda G. 2009. ROS generation in plants: Boon or bane? Plant Biosyst. 143: 81-96.

Gill SS, Tuteja N. 2010. Reactive oxygen species and antioxidant machinery in abiotic stress tolerance in crop plants. Plant Physiol. Biochem. 48: 909-930.
Kalimullah M, Gaikwad JU, Thomas S, Sarma A, Vidyasagar PB. 2003. Assessment of $1 \mathrm{H}$ heavy ion irradiation induced effects in the development of rice (Oryza sativa L.) seedlings. Plant Sci. 165: 447-454.

Kim DY, Hong MJ, Park CS, Seo YW. 2015. The effects of chronic radiation of gamma ray on protein expression and oxidative stress in Brachypodium distachyon. Int. J. Radiat. Biol.91: 407-419.

Kim, SH, Song M, Lee KJ, Hwang SG, Jang CS, Kim JB, et al. 2012. Genome-wide transcriptome profiling of ROS scavenging and signal transduction pathways in rice (Oryza sativa L.) in response to different types of ionizing radiation. Mol. Biol. Rep. 39: 11231-11248.

Kiong L, Lai AG, Sobri H, Abdul RH. 2008. Physiological responses of Orthosiphon stamineus plantles to gamma irradiation. American-Eurasian Journal of Sustainable Agriculture 2: 135-149.

Lee JD. 2012. Environmental effects on oleic acid in soybean seed oil of cultivar Kwangan. Kor. J. Breed. Sci. 44: 29-34.

Lee JH, Lee AR, Kwon SW. 2015a. Effect of proton beam irradiation on M1 seeds and seedling growth in rice. Plant Breed. Biotech. 3: 384-388.

Lee YM, Jo YD, Lee HJ, Kim YS, Kim DS, Kim JB, et al. 2015b. DNA damage and oxidative stress induced by proton beam in Cymbidium hybrid. Hort. Environ. Biotechnol. 56: 240-246.

Lee YM, Lee HJ, Kim YS, Kang SY, Kim DS, Kim JB, et al. 2016. Evaluation of the sensitivity to ionising $\gamma$-radiation of a Cymbidium hybrid. J. Hortic. Sci. Biotechnol. 91: 109-116.

Ling APK, Ung YC, Hussein S, Harun AR, Tanaka A, Yoshihiro H. 2013. Morphological and biochemical responses of Oryza sativa L. (cultivar MR219) to ion beam irradiation. Journal of Zhejiang University-SCIENCE B 14: 1132-1143.

Marcu D, Damian G, Cosma C, Cristea V. 2013. Gamma radiation effects on seed germination, growth and pigment content, and ESR study of induced free radicals in maize (Zea mays). J. Biol. Phys. 39: 625-634.

Nakano Y, Asada K. 1981. Hydrogen peroxide is scavenged by ascorbate-specific peroxidase in spinach chloroplasts. Plant Cell Physiol. 22: 867-880.

Ni Z, Kim ED, Ha M, Lackey E, Liu J, Zhang Y, et al. 2009. Altered circadian rhythms regulate growth vigour in 
hybrids and allopolyploids. Nature 457: 327-331.

Oh BK, Hong KA, Song SJ, U ZK, Lee SJ, Lee YI. 2003. Gamma radiation sensitivity and quantitative characters in M1 generation of Heteropappus hispidus (Thunb.). Korean Journal of Environmental Agriculture 22: 294-299.

Scandalios JG. 1993. Oxygen stress and superoxide dismutases. Plant Physiol. 101: 7-12.

Sharma P, Jha AB, Dubey RS, Pessarakli M. 2012. Reactive oxygen species, oxidative damage, and antioxidative defense mechanism in plants under stressful conditions. Journal of Botany 2012: 1-26.

Suh SK, Kim HS, Oh YJ, Kim KH, Cho SK, Kim YJ, et al. 1997. A new soybean variety for sprout with small seed and high yielding "Pungsan-namul". Kor. J. Breed. Sci. 29: 503.

Sung SY, Lee YM, Kim SH, Ha, BK, Kang, SY, Kim, JB, et al. 2013. Comparative analysis of growth and antioxidant enzyme activities from two chrysanthemum varieties, 'ARTT-purple' and 'ARTT-queen' by chronic irradiation of gamma-ray. Kor. J. Hort. Sci. Technol. 31: 490-495.

Tanaka A, Shikazono N, Hase Y. 2010. Studies on biological effects of ion beams on lethality, molecular nature of mutation, mutation rate, and spectrum of mutation phenotype for mutation breeding in higher plants. J. Radiat. Res. 51: 223-233.

Voitsekhovskaja OV, Tyutereva EV. 2015. Chlorophyll b in angiosperms: Functions in photosynthesis, signaling and ontogenetic regulation. J. Plant Physiol. 189: 51-64.

Weisany W, Sohrabi Y, Heidari G, Siosemardeh A, Ghassemi-Golezani K. 2012. Changes in antioxidant enzymes activity and plant performance by salinity stress and zinc application in soybean (Glycine max L.). Plant Omics J. 5: 60-67.

Wi SG, Chung BY, Kim JS, Kim JH, Baek MH, Lee JW, et al. 2007. Effects of gamma irradiation on morphological changes and biological responses in plants. Micron 38: 553-564.

Zhang L, Xiao S, Li W, Feng W, Li J, Wu Z, et al. 2011. Overexpression of a Harpin-encoding gene hrfl in rice enhances drought tolerance. J. Exp. Bot. 62: 4229-4238.

Zhao SP, Huang QC, Liang QX, Zhang SG, Jiao Z, Huang WZ. 2013. Biological effects of low energy $N+$ beams implantation on calluses of autotetraploid rice. J. Integr. Agric. 12: 2045-2055. 